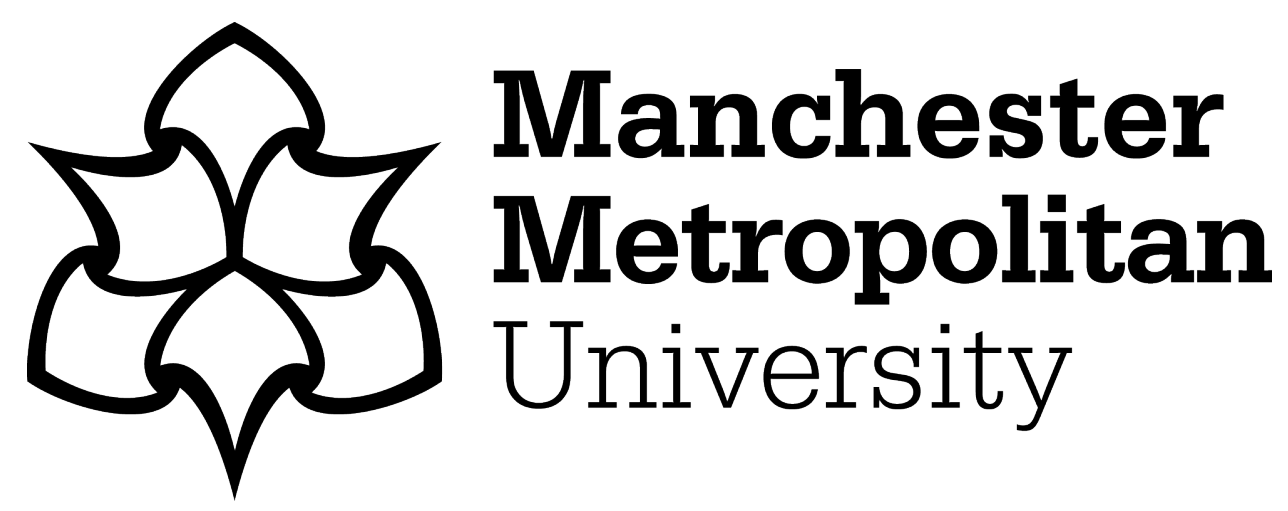

Karamanlioglu, M, Preziosi, R ORCID logoORCID: https://orcid.org/00000003-0468-6655 and Robson, GD (2017) Abiotic and biotic environmental degradation of the bioplastic polymer poly(lactic acid): A review. Polymer Degradation and Stability, 137. pp. 122-130. ISSN 0141-3910

Downloaded from: https://e-space.mmu.ac.uk/623422/

Version: Accepted Version

Publisher: Elsevier

DOI: https://doi.org/10.1016/j.polymdegradstab.2017.01.009

Usage rights: Creative Commons: Attribution-Noncommercial-No Derivative Works 4.0

Please cite the published version 


\title{
Abiotic and biotic environmental degradation of the bioplastic polymer poly(lactic acid): A review
}

\author{
Mehlika Karamanlioglu a , Richard Preziosi ${ }^{\mathrm{b}}$, Geoffrey D. Robson ${ }^{\mathrm{a}, *}$ \\ ${ }^{a}$ Faculty of Biology, Medicine and Health, School of Biological Sciences, Michael Smith Bld, University of Manchester, Manchester, M13 9PT, UK \\ ${ }^{\mathrm{b}}$ Division of Biology and Conservation Ecology, Manchester Metropolitan University, Manchester, M15 6BH, UK
}

\begin{abstract}
A B S T R A C T
Poly(lactic acid) (PLA) is a compostable bioplastic manufactured by the polymerization of lactic acid monomers derived from the fermentation of starch as a feedstock. Since its first commercialisation in the late 1990 's, PLA production has grown annually and currently it estimated that worldwide production will reach at least 800,000 tons by 2020 with Japan and the USA the two major producers. PLA is used as a replacement to conventional petrochemical based plastics, principally as food packaging containers and films and more recently, in electronics and in the manufacture of synthetic fibres. Consequently, there has been a marked increase in PLA contamination in the environment as well as increasing amounts being diverted to commercial composting facilities. This review focuses on the development, production, stability and degradation of PLA in a range of differing environments and explores our current knowledge of the environmental and biological factors involved in PLA degradation.
\end{abstract}

\section{Contents}

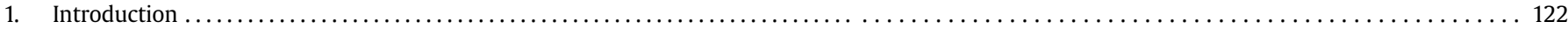

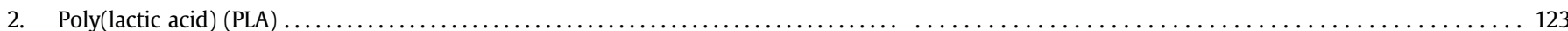

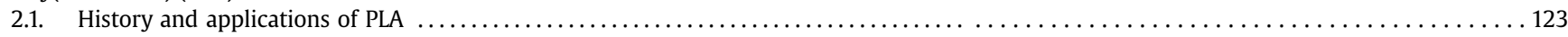

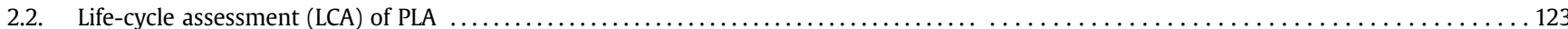

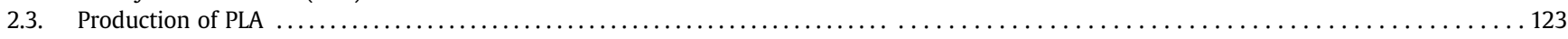

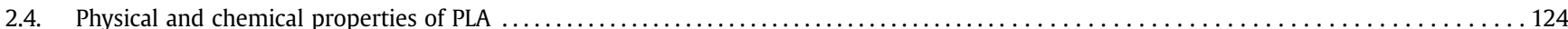

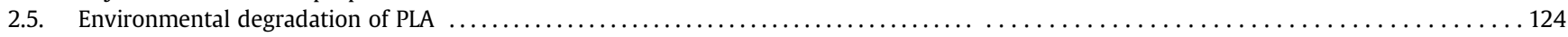

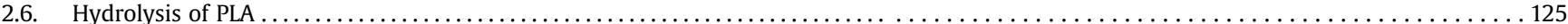

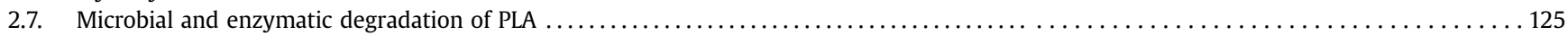

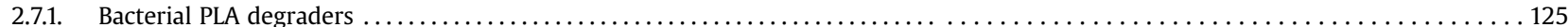

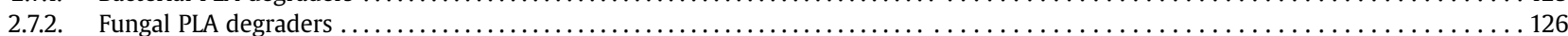

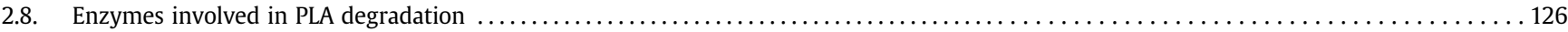

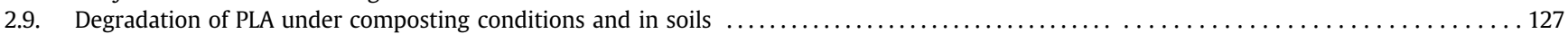

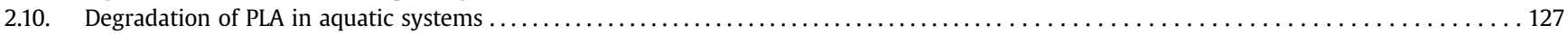

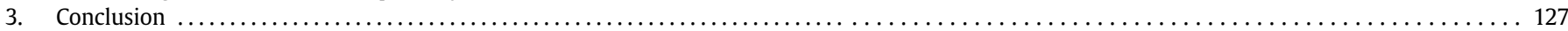

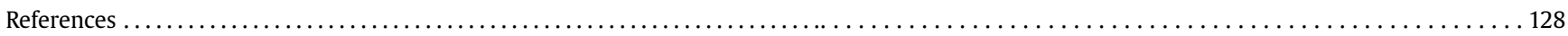

\footnotetext{
* Corresponding author.

E-mail address: geoff.robson@manchester.ac.uk (G.D. Robson).
}

\section{Introduction}

Degradable plastics are polymers that undergo changes in their chemical structure in specific environmental conditions causing significant loss in physical and mechanical properties as defined by 
the American Society for Testing of Materials (ASTM) and the International Standards Organization (ISO). Within this definition, biodegradable plastics are susceptible to degradation by enzymes produced by microorganisms including bacteria, fungi and algae [1]. Biopolymers (bioplastics) are in general biodegradable polymers that are produced from renewable natural sources such as polysaccharides (e.g. cellulose, starch and chitin), lipids (oils), proteins (e.g. gelatine and gluten), plant/microbial polyesters (polyhydroxyalkanoates, e.g. polyhydroxybutanoates) [2]; or synthesized from renewable resources such as polyesters produced from bio-derived monomers (such as polylactic acid from starch) $[3,4]$. During the biodegradation process, biodegradable polymers are broken down to their simpler constituent components and redistributed through elemental cycles such as the carbon and nitrogen cycles and the ultimate end products of the degradation process are carbon dioxide, water, and biomass under aerobic conditions and hydrocarbons, methane, and biomass under anaerobic conditions $[5,6]$.

\section{Poly(lactic acid) (PLA)}

Poly(lactic acid) (PLA) is a synthetic bio-based polyester derived from starch feedstocks with a hydrolysable backbone that is susceptible to biodegradation [7-13]. The general structure of PLA is shown in Fig. 1. PLA has gained importance due to its mechanical properties which are similar to the petrochemical based plastics polystyrene (PS) and polyethylene terephthalate (PET) [14,15]. It has a number of favourable properties including ease of fabrication, zero toxicity, biocompatibility, high mechanical strength and thermal plasticity and is compostable [7-9,12-14,16-23]. Most importantly its raw material, lactic acid, can be obtained from renewable resources, principally starch $[14,24,25]$. As PLA is a polymer synthesized from renewable resources, it has been suggested that its use could help to lower greenhouse gas emissions and reduce fossil energy consumption compared to conventional petrochemical-based polymers [24]. However, the ever increasing diversion of starch feedstocks such as maize to PLA production also brings pressures on land use and agriculture [26].

\subsection{History and applications of PLA}

William Carothers pioneered the production of an aliphatic polyester from lactic acid in 1932, however, the resulting polymer had poor mechanical properties and a low molecular weight [27]. In 1954, DuPont (USA) developed and patented a higher molecular weight polymer of this polyester [28]. As PLA is a non-toxic, biocompatible material with high mechanical strength that hydrolyses slowly in the body, the use of PLA was initially restricted to medical applications $[7,14,29,30]$. In addition, high cost of production from the petrochemical-derived precursor lactic acid, further restricted its development into other applications. However, costs of PLA production decreased markedly when lactic acid began to be produced by bacterial fermentation of starch, enabling commercial scale production for non-medical applications $[1,14]$.

Cargill Dow LLC, (USA) and Teijin (Japan) are the principal

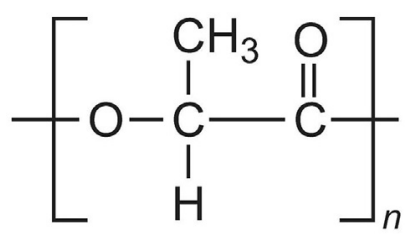

Fig. 1. Monomeric subunit of polymeric PLA containing $\mathrm{n}$ residues. manufacturers of PLA and have developed applications for PLA in packaging and fibres [18,31,32]. In 1997, Cargill Dow LLC was founded as a 50/50 joint venture between Cargill Inc. and The Dow Chemical Company to commercialize PLA polymers under the trade name NatureWorks ${ }^{\mathrm{TM}}$ [24]. Currently, Cargill Dow LLC, has become the primary producer of PLA in the USA manufacturing 140,000 tons of PLA annually for the production of packaging and fibre materials [20,33]. Toyota (Japan), PURAC Biomaterials (The Netherlands), Hycail (The Netherlands), Galactic (Belgium), DURECT (US) and several Chinese manufacturers represent the remaining companies involved in PLA production. In 2012, the worldwide PLA production was c.a. 180,000 tons and it is estimated that PLA production will reach at least 800,000 p.a. by 2020 (Fig. 2).

Fibres, non-woven, rigid and flexible strong materials can be produced from high molecular weight PLA (100,000 Da and higher). Apart from its use in the medical field [7,29,30], PLA has been commercialised for the manufacture of compostable short shelf-life products such as food-packaging films, bags and containers with the majority currently used for containers (Fig. 3) $[8,14,17,24,33]$. NatureWorks ${ }^{\mathrm{TM}}$ branded PLA as a biobased compostable polymer and The Food and Drug Administration approved PLA to be used for producing materials in contact with food [24,33]. Although principally used in food applications, PLA is increasingly being used in non-food related applications including electronics, synthetic fibres, wrapping films and tapes. Ingeo ${ }^{\mathrm{TM}}$ fibers, first produced by Cargill Dow in 2003, are the first synthetic fibres made from $100 \%$ annually renewable sources and are used in pillows, mattresses and duvets, apparel and floor, wall and furniture textiles, [20,24,33]. PLA also has applications in cosmetics and is being exploited for 3-D printers [34].

\subsection{Life-cycle assessment (LCA) of PLA}

Life-cycle assessment (LCA) is a method to quantify the environmental sustainability of a product or a process [25]. The 'lifecycle' comprises all stages in a product's life from manufacture to disposal [25]. Production of raw materials, resource extraction, transportation, product manufacture, end use and ultimate disposal are all integral to the LCA and also identifies actions contributing to the economy and environment [25]. Fossil energy requirement, greenhouse gases and water use can be classified as three life cycle impact categories for PLA [24]. According to Cargill Dow in 2003, the PLA production system uses 25-55\% less fossil energy than petroleum-based polymers [24,25]. While disposal of PLA products (combustion, composting, etc.) causes carbon dioxide release to the atmosphere, it can be considered as a low-impact greenhouse gas polymer compared to petrochemical-based polymers as the $\mathrm{CO}_{2}$ generated during PLA biodegradation is balanced by an equal amount removed from the atmosphere during the growth of the plant feedstocks [25]. PLA greenhouse gas emission rate is about $1600 \mathrm{~kg} \mathrm{CO}_{2}$ /metric ton, while PP, PET, and nylon have greenhouse gas values of $1850,2740,4140$, and $7150 \mathrm{~kg} \mathrm{CO}_{2} /$ metric ton respectively [23]. The third impact category, water required for PLA production, is less than that required for petrochemical-based polymers. LCA shows that PLA production processes are both fossilenergy free and a source of carbon credits over the longer term [24].

\subsection{Production of PLA}

Lactic acid (2-hydoxypropionic acid) is the monomer of PLA and exists as two stereoisomers in nature; L-lactic acid and D-lactic acid [14]. Lactic acid is a naturally occurring water soluble organic acid and can be produced either by chemical synthesis from petrochemicals or fermentation $[14,25]$. When lactic acid is generated from petrochemicals, it exists in the meso-form, a 50/50 mixture of 


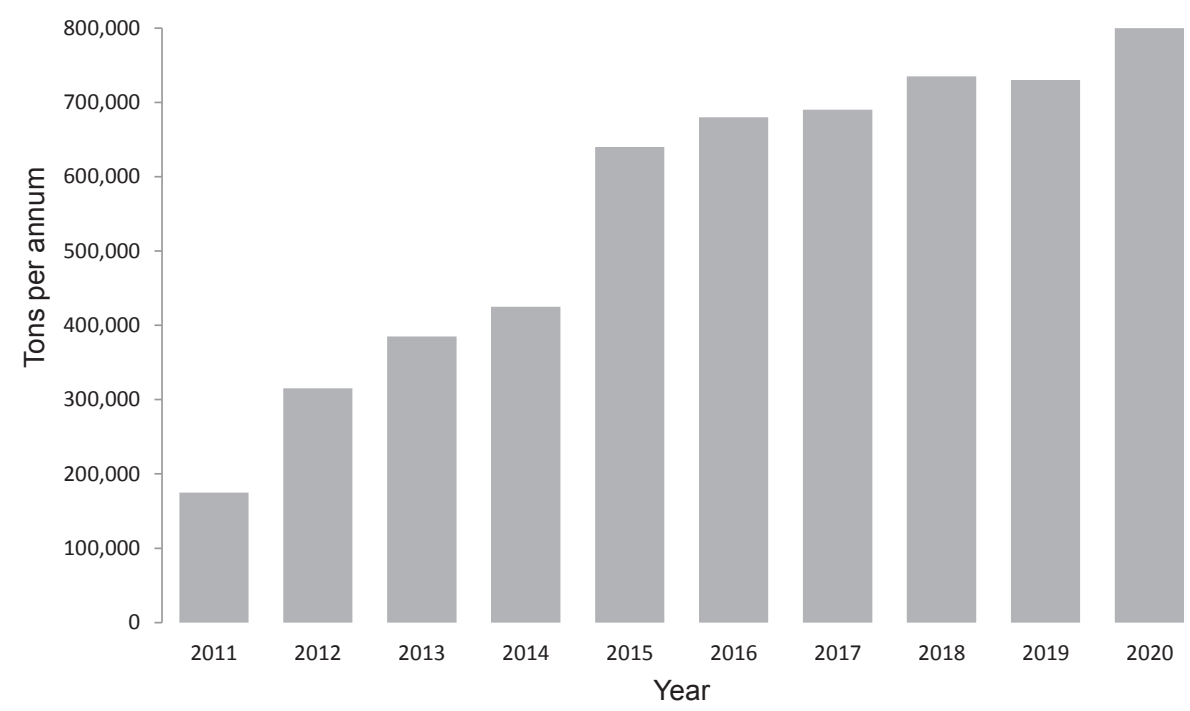

Fig. 2. Production and forecast for global PLA production (adapted from Nova Institute, 2012).

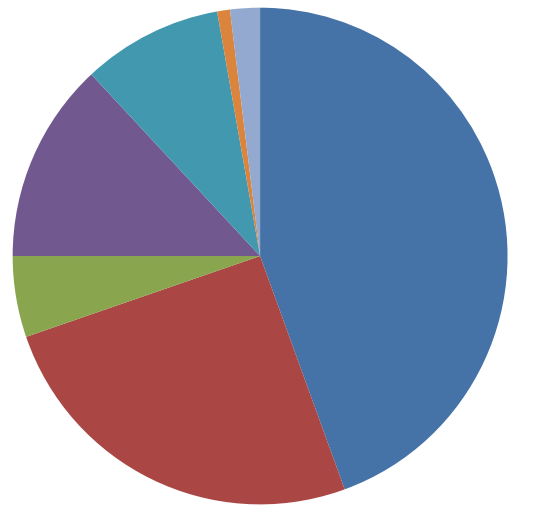

- Packaging (incl bottles)

- Catering

- Agriculture

- Technical materials

- Consumer goods

Construction

Others

Fig. 3. Global PLA application market in 2013 (Adapted from Occams Business Research \& Consultancy).

the $\mathrm{L}$ and $\mathrm{D}$ isomers, and it is optically inactive [14]. Fermentation based generation of lactic acid has a lower environmental impact as it uses renewable resources instead of petrochemicals, consumes less energy and is cheaper to produce $[33,35]$. Lactic acid production by fermentation of carbohydrates involves: (a) fermentation, (b) cell mass and protein removal, (c) recovery and purification, (d) concentration, and (e) colour removal $[13,25]$. When lactic acid is produced by fermentation, it is composed largely of L-lactic acid, generally 99.5\% L-isomer and 0.5\% D-isomer [11,14,24,25]. Production of PLA from lactic acid then proceeds through direct condensation polymerization [18], azeotropic dehydrative condensation polymerization [36] or ring-opening polymerization through a lactide intermediate [8,24,37].

\subsection{Physical and chemical properties of PLA}

PLA is a aliphatic (linear) polyester consisting of polymerized lactic acid monomers linked by ester bonds (Fig. 1) PLA can be amorphous or semicrystalline in its solid state depending on the enantiomers composition and thermal history [11,25,38]. Semicrystalline polymers contain both crystalline and amorphous regions. When the D-isomer is present at less than 6\%, the PLA polymer is semicrystalline; however when the D-isomer is more than $6 \%$, the sample is considered to be amorphous $[39,40]$.

Homopolymers of PLA containing only the L-isomer is crystalline [11]. Optical composition and therefore crystallinity affect melting temperature (Tm), glass transition temperature $(\mathrm{Tg})$ and mechanical properties of PLA. The decreasing optical purity (increasing Disomer) decreases crystallinity, Tm and mechanical properties [20,25,41-43]. High molecular weight Poly (L-lactide) has a melting point of $180^{\circ} \mathrm{C}$, while the introduction of meso-lactide depresses the crystalline melting point to $130^{\circ} \mathrm{C}$ [38]. Since crystalline regions of PLA are stronger and therefore more resistant to degradation $[38,44]$, crystallinity of PLA has benefits including improved heat setting, chemical resistance, higher strength in fibers/non-wovens, heat resistance and stiffness in cutlery, permeability and chemical resistance in films $[14,25]$. It has been reported that degradation is faster in amorphous domains of PLA specimens compared to semicrystalline and crystalline forms $[45,46]$. Therefore, for biomedical devices, amorphous PLA, (i.e. containing higher levels of D-isomer) is mostly preferred, whereas semi-crystalline PLA is mostly used in applications where higher mechanical properties are desired [47].

High molecular weight PLA (Mw $>100,000$ D) is generally characterized by high mechanical strength with a tensile strength in the region of $50-70 \mathrm{MPa}$ which is comparable to nonbiodegradable conventional plastics [14,15,47]. Amorphous polymers and semi-crystalline polymers are brittle at low temperatures but soften at the glass transition temperature $(\mathrm{Tg})$ [48]. If the heating process is continued above $\mathrm{Tg}$, polymers become viscous and finally turn into a liquid form. For semicrystalline PLA, both Tg and Tm determine the upper use temperature of PLA materials and since crystalline polymers do not have amorphous regions, they do not show glass transition and their crystalline structure melts at their melting temperature [12,13].

\subsection{Environmental degradation of PLA}

In nature, biotic and abiotic factors exist together; therefore, the whole degradation mechanism of a certain material can be referred as environmental degradation $[4,25]$. The environmental degradation process of PLA is affected by its material properties such as molecular 1st order structure (molecular weight, optical purity) and higher order structures (crystallinity, $\mathrm{Tg}$ and $\mathrm{Tm}$ ), and by environmental factors such as humidity, temperature and catalytic species ( $\mathrm{pH}$ and the presence of enzymes or microorganisms) $[49,50]$. When the molecular weight is low, (Mw $<100,000$ D) PLA 
is brittle, cloudy and opaque while at higher molecular weights, PLA is stronger, more transparent and less susceptible to degradation [51]. Crystalline regions within PLA hydrolyse much more slowly than the amorphous regions as water diffuses more readily into the less organized amorphous regions compared to the more ordered crystalline regions, causing greater rates of hydrolysis and increased susceptibility to biodegradation [16,20,25,44,52]. In semicrystalline PLA, degradation occurs first in the amorphous regions and more slowly in the crystalline regions. Therefore, with time, the proportion of the crystaline regions within the PLA increases and the rate of degradation decreases [25,53,54]. Increasing concentrations of D-units in PLA lowers optical purity and regularity, leading to greater water diffusion through the polymer matrix in the amorphous regions and accelerating hydrolysis [54,55]. The rate of PLA degradation is much greater above the glass transition temperature $\left(\mathrm{Tg}, 55-62^{\circ} \mathrm{C}\right)$ as polymer chains become more flexible and water absorption increases, accelerating both hydrolysis and microbial attachment [20,25,44].Temperatures at or above $\operatorname{Tg}\left(55-62{ }^{\circ} \mathrm{C}\right)$ and at high relative humidity's (>60\%), PLA hydrolysis is rapid [17,51,56,57].

In its molten state, PLA can also undergo thermal denaturation [11] as hydrolysis can occur in the presence of small traces of water or in the absence of water, PLA undergoes zipper like depolymerazion, oxidative random chain scission, intermolecular or intramolecular transesterification to monomers and oligomers [58].

PLA degradation is also known to be influenced by $\mathrm{pH}$ and UV light. PLA degrades faster in alkaline conditions because during hydrolysis, cleavage of ester groups is catalysed by hydroxide ions, therefore, the high concentration of hydroxide ions in alkaline media enhances PLA degradation [52,59]. UV light exposure was also found to affect PLA degradation [60-63]. When PLA films were exposed to UV light for 8 weeks under a low relative humidity (10\%, which restricts the rate of PLA hydrolysis), UV light decreased the physical integrity and enhanced PLA degradation [60]. In addition, electron beam irradiation has also been shown to effect PLA integrity. Pre-treating PLA by electron beam irradiation increased PLA brittleness and decreased molecular weight during compost degradation compared to non-irradiated samples [64]. In another study, treatment of films by electron-beam irradiation decreased the average molecular weight, stress at break and percentage elongation [60]. Cairns et al. [65], also showed that depending on the beam energy used, physical properties, molecular weight were affected increasing the degradation rate of PLA. PLA degradation is generally accepted to be a two-step mechanism involving first abiotic factors then biotic factors. The abiotic process, which is the chemical hydrolysis of PLA in the presence of water at elevated temperatures, is followed by biotic degradation in which microorganisms decompose polymer break-down products generating carbon dioxide, water and biomass under aerobic conditions and methane, hydrocarbons and biomass under anaerobic conditions $[12,14,17,18,20,25,66-71]$. While some studies have reported that microorganisms do not enhance PLA degradation [56], other studies have suggested that microbial enzymes exist that are capable of directly degrading high molecular weight PLA [72-74].

\subsection{Hydrolysis of PLA}

PLA is an aliphatic (linear) polyester and unlike aromatic polyesters, which have aromatic rings, PLA is susceptible to hydrolysis due to the hydrolysable functional groups in its backbone $[12,18,50]$. Chemical hydrolysis of the ester linkages occurs in the presence of water, hydrolysing the backbone of the polymer as shown in the following reaction:

$-\mathrm{COO}-+\mathrm{H}_{2} \mathrm{O} \rightarrow-\mathrm{COOH}+\mathrm{HO}$
A random non-enzymatic chain scission of ester groups is followed by chain-end hydrolysis causing a reduction in molecular weight [25]. Carboxylic acid end groups of PLA and its oligomers can catalyse the ester linkages since the pKa of PLA's carboxylic acid end group and its oligomers is lower $(\sim 3)$ than most carboxylic acid groups (4.5-5) leading to faster rate of degradation (autocatalysis) [25]. Amorphous PLA chains are far more susceptible to hydrolysis compared to crystalline regions and by contrast hydrolysis occurs at a much slower rate $[46,75,76]$.

Hydrolysis of PLA has mostly been studied in relation to its medical applications as PLA materials and devices are designed to hydrolyse in the body fluids [45,66,77-79]. PLA devices are firstly hydrolysed by body fluids by absorbing water causing autocatalytic cleavage of ester bonds. Large size devices having more than $1 \mathrm{~mm}$ thickness are thought to degrade faster inside than at the surface during chemical hydrolysis and this is attributed to a diffusionreaction phenomena with soluble oligomers metabolised by the cells in the body $[19,66,77]$. In general, it is thought that PLA with a smaller surface/volume ratio hydrolyse more slowly [38]. Complete hydrolysis of PLA at $37{ }^{\circ} \mathrm{C}$ in physiological media has been reported to occur over a 5 year period when used as orthopaedic devices [78]. When PLA degradation was studied at $37{ }^{\circ} \mathrm{C}$ [79], 50 and $70{ }^{\circ} \mathrm{C}$ [80] in PBS, maximum weight loss was $4 \%$ at $50{ }^{\circ} \mathrm{C}$ after 115 days and $7.6 \%$ at $70{ }^{\circ} \mathrm{C}$ after 23 days.

Many studies consider abiotic hydrolysis as the main degradation step as high humidity and temperature enables the cleavage of the ester linkages by water uptake causing reduction in molecular weight; with microorganisms assimilating acid lactic oligomers, releasing carbon dioxide and water $[12,14,17,18,20,25,56,66-71]$.

\subsection{Microbial and enzymatic degradation of PLA}

With the recent commercialisation of PLA for short-shelf life products, degradation of PLA in the environment has increasingly become the focus of research. However, degradation mechanisms of PLA and understanding the association and role of microorganisms during the environmental degradation are still poorly understood $[19,68]$. The most commonly suggested mechanism is that microorganisms can degrade PLA only after high molecular weight PLA goes under hydrolysis and the molecular weight of PLA falls 10,000 Da or less $[14,17,18,20,25,56,66-71]$. This is a distinct feature of PLA because typically biodegradable polymers are degraded by microbial attack in a single step [14]. When the degradation rates of PLA in a biotic reactor containing compost were compared with an abiotic reactor lacking compost and a sterile aqueous system, similar degradation rates were observed and it was concluded that there was no evidence for the enhanced degradation of PLA by microorganisms [56]. Isolation of PLA degraders especially by cultivation methods have been challenging, for instance, one study aimed to identify soil bacteria that were able to degrade commercially available aliphatic polyesters, including PLA, and when microorganisms were extracted from 3 different soil samples and screened on agarplates containing different polyester materials, no PLA degrading organisms were found although some strains were identified for most polyesters tested [81]. However, other studies have suggested that microbes may have a direct effect on PLA degradation, as outlined below.

\subsubsection{Bacterial PLA degraders}

A number of studies over the last 15 years have isolated putative PLA degrading bacteria. The first identified bacterium was an actinomycete, Amycolatopsis HT-32, but was isolated from only 1 out of 45 soil samples [82]. Subsequently, further studies have isolated a number of different actinomycete and some other bacterial PLA degraders and these are outlined in Table 1. Putative PLA degraders 
Table 1

Putative bacterial PLA degraders.

\begin{tabular}{ll}
\hline Organism & Reference \\
\hline Amycolatopsis sp. HT 32 & {$[82]$} \\
Amycolatopsis sp. KT-s-9 & {$[115]$} \\
Amycolatopsis sp. 3118 & {$[116]$} \\
Amycolatopsis mediterranei ATCC 27643 & {$[117]$} \\
Amycolatopsis sp. KT-s-9 & {$[118]$} \\
Amycolatopsis sp. 41 & {$[94]$} \\
Amycolatopsis orientalis & {$[84]$} \\
Saccharothrix (Lentzea) sp. & {$[84]$} \\
Saccharothrix waywayandensis & {$[119]$} \\
Kibdelosporangium sp. & {$[84]$} \\
Kibdelosporangium aridum & {$[120]$} \\
Streptoalloteichus sp. & {$[84]$} \\
Bacillus brevis & {$[121]$} \\
Bacillus smithii & {$[122]$} \\
Bacillus stearothermophilus & {$[123]$} \\
Geobacillus thermocatenulatus & {$[124]$} \\
Bacillus sp. & {$[125]$} \\
Thermomonospora sp. & {$[67]$} \\
Thermopolyspora sp. & {$[67]$} \\
Actinomadura keratinilytica T16-1 & {$[126]$} \\
Laceyella sacchari T11-7 & {$[126]$} \\
Nonomuraea strains & {$[126]$} \\
Thermoactinomyces vulgalis & {$[126]$} \\
Bordetella petrii PLA-3 & {$[127]$} \\
Stenotrophomonas maltophilia LB 2-3. & {$[128]$} \\
Thermopolyspora flexuosa & {$[91]$} \\
Pseudonocardia sp. RM423 & {$[110]$} \\
\hline
\end{tabular}

have generally been isolated by cultivation methods from soil or compost with the exception of studies conducted by Sangwan and $\mathrm{Wu}$ [68] and Sangwan et al. [83] that generated clone libraries to identify putative PLA degraders from compost. Most of the bacteria isolated earlier belong to the same family Pseudonocardiaceae genera Amycolatopsis, Saccharothrix, Streptoalloteichus, Kibdelosporangium $[68,83,84]$. More bacteria belonging to other families, Thermomonosporaceae, Micromonosporaceae, Streptosporangiaceae, Bacillaceae and Thermoactinomycetaceae, have been isolated more recently $[68,85]$.

\subsubsection{Fungal PLA degraders}

Most studies to date have focused on bacterial PLA degraders, however, there are few studies that have considered a role for fungi in PLA degradation (Table 2). Tritirachium album was the first fungus reported in the literature to be capable of PLA degradation $[72,86]$. However, in the earliest study, the fungus itself was not directly tested with PLA, the enzyme proteinase $\mathrm{K}$ was isolated from T. album ATCC 22563 and incubated with PLA [86]. When the same strain was directly grown on agar emulsified with PLA, no clear zone was formed around the strain on the plate [82]. Moreover, when T. album ATCC 22563 was incubated in liquid medium containing PLA, degradation was only observed in the presence of gelatin which induced protease production [72].

Table 2

Putative fungal PLA degraders.

\begin{tabular}{ll}
\hline Organism & Reference \\
\hline Fusarium moniliforme & {$[87,88]$} \\
Penicillium roqueforti & {$[88]$} \\
Tritirachium album & {$[72,86]$} \\
Paecilomyces sp. & {$[68]$} \\
Cryptococcus sp. & {$[73]$} \\
Eurotiomycetes species & {$[83]$} \\
Aspergillus fumigatus & {$[90]$} \\
Thermomyces lanuginosus & {$[90]$} \\
Trichoderma viride & {$[129]$} \\
\hline
\end{tabular}

Fusarium moniliforme was shown to be capable of utilizing low molecular weight PLA degradation by-products, including lactic acid, lactillactic acid dimers, and higher oligomers in liquid culture [87]. In another study out of 14 fungal strains tested, 2 strains of F. moniliforme and 1 strain of Penicillium roqueforti were able to use DL-lactic acid and DL-lactic acid oligomers as sole carbon sources after 7 days of incubation in liquid culture [88]. A high molecular weight PLA copolymer with glycolic acid (PLAGA) was also inoculated with fungal strains and one strain, $F$. moniliforme was able to grow on the samples after 2 months [88]. As a result, it was concluded that, after abiotic degradation, this strain was able to utilise low molecular weight breakdown products [88].

Sangwan and $\mathrm{Wu}$ [68] used molecular methods to isolate putative high molecular weight PLA degraders. In their study, solid PLA samples were buried in compost and samples were taken from the initial compost and from the surface of the polymer specimens after 60 days of composting at $58^{\circ} \mathrm{C}$. Clone libraries were generated from $18 \mathrm{~S}$ rDNA recovered from the PLA surface and it was suggested that the class Eurotiomycetes (genus Paecilomyces) may play significant roles in biodegradation of PLA under composting conditions. In a further study by Sangwan et al. [83], degradation of neat and nanocomposites of PLA was studied and fungi belonging to class Eurotiomycetes were again identified from the compost samples on PLA discs buried in mature compost at $58^{\circ} \mathrm{C}$ by clone library generation. Saadi et al. [71] studied fungal degradation of high molecular weight PLA by inoculating fungi into sterilized compost and comparing the degradation rate with unsterile compost. This study indicated a synergy between bacteria and fungi in PLA degradation as the degradation rate was higher in unsterile compost [71]. Likewise, a study investigating PLA degradation at $50{ }^{\circ} \mathrm{C}$ demonstrated an increase in degradation rate in unsterile compared to sterile compost and soil [89]. Two thermophilic fungi (Thermomyces laniginosa and Aspergillus fumigatus) were subsequently isolated and shown to be capable of PLA degradation [90]. However, another study [91] comparing abiotic hydrolysis and biodegradation concluded that microbial enzymes were not significant factors in accelerating depolymerisation.

\subsection{Enzymes involved in PLA degradation}

There have been few studies that have focused on microbial enzymes potentially involved in the degradation of PLA. Ebeling et al. [92] identified a serine protease, proteinase $K$, from the filamentous fungus Tritirachium album and Williams [86] identified proteinase $\mathrm{K}$ from T.album as an enzyme capable of degrading PLA. However, PLA degradation by T. album ATCC 22563 only occurred in the presence of gelatin which induced protease production [72]. No degradation was observed in the absence of gelatin after 14 days, whereas in the presence of $0.1 \%$ gelatin, $76 \%$ of the high molecular weight PLA film was degraded by the fungus [72]. The presence of gelatin in the culture medium has been reported to enhance microbial degradation of high molecular weight PLA films which are not usually attacked by microorganisms [72]. Watanabe et al. [74] also studied the enzymatic degradation of high molecular weight PLA with commercial proteinase $\mathrm{K}$ by treating emulsified PLA with the enzyme and after $5 \mathrm{~h}$ incubation; it was observed that $60 \%$ of PLA was consumed. However Tsuji \& Ikarashi [76], reported no catalytic degradation of crystalline PLA by proteinase $\mathrm{K}$ indicating that crystalline regions are highly resistant to protease degradation compared to amorphous regions. When commercially available lipases from various microorganisms were tested for their ability to degrade several aliphatic polyesters including PLA, none of them were able to degrade high molecular weight PLA at $37^{\circ} \mathrm{C}$ although they could degrade the rest of the aliphatic polyester films tested [93] whereas Pranamuda et al. [94] purified an enzyme from 
Amycolatopsis which degraded PLA but not the other aliphatic polyesters polycaprolactone (PCL) and polyhydroxybutyrate (PHB).

Microbial enzymes degrading PLA were found to be induced by some proteins, peptides and amino acids [95]. It was found that PLA degrading activity of $A$. orientalis was induced by silk fibroin and PLA degrading activity of $L$. waywayandensis and T.album was induced by elastin suggesting these inducers could be used to enhance degradation of PLA waste and also used in the large scale production of PLA degrading enzyme [95]. An enzyme referred as cutinase-like enzyme (CLE) purified from the yeast Cryptococcus sp. completely degraded high molecular weight PLA and at a faster rate than proteinase $\mathrm{K}[65,73]$. Cryptococcus sp. generally has been used in waste treatment and CLE was found to exhibit a weak homology to cutinase [73]. It has also been reported that Amycolatopsis orientalis ssp. orientalis produced three serine-like proteases capable of degrading PLA as a sole carbon source [96]. Another serine protease isolated from an actinomycete, Actinomadura, was also reported to be capable of degrading PLA [85].

\subsection{Degradation of PLA under composting conditions and in soils}

PLA has recently been commercialised for the manufacture of compostable food-packaging films, bags and containers and its decomposition under composting conditions is well established $[8,14,17,24]$. Compost is a humic, organic-rich, biological environment where the environmental degradation of organic matter occurs [17]. Compost contains diverse microbial populations since it has a unique physical and nutritional structure [68]. Composting is the controlled biological decomposition of organic materials into humus by microorganisms in aerobic conditions [20,97] and is a versatile system for processing biodegradable solid wastes [98]. Compostable plastics, as defined by the ASTM [99], are polymers that are decomposed by biological activity to $\mathrm{CO}_{2}$, water, inorganic compounds and biomass without leaving any visible and toxic residues. Composting is particularly well suited for processing food contaminated packaging since recycling facilities are not equipped to deal with food contaminated plastics and compost formed at the end of the process is a valuable product used in soil amendment [40].

Composting is mostly a microbiological process based on activities of fungi, bacteria and actinomycetes which decompose complex organic substrates to simpler compounds [20,97,100]. The initial mesophilic phase where microorganisms break-down simple molecules is replaced with a thermophilic phase with temperatures rising to up to $60^{\circ} \mathrm{C}$ or higher due to microbial activity [101]. During the cooling phase the cooling phase, temperature gradually decreases to ambient temperatures and humus-like substances are produced [97,102]. Degradation occurs at a slower rate and continues until all the readily utilizable carbon is converted to carbon dioxide [20,97]. Decomposition and humification occur simultaneously to degrade organic matter [98].

PLA can be degraded in a composting environment after 45-60 days at $50-60{ }^{\circ} \mathrm{C}$ by microorganisms in the compost [19]. When biodegradation of PLA film and fabrics was studied in a bench scale composting system, PLA fabrics were degraded after 40 days and PLA sheets after 20 days [17]. Commercially available PLA bottles and PLA delicatessen containers degraded visibly in 30 days under composting conditions with PLA bottles having a lower degradation rate due to a higher degree of crystallinity [20]. Both PLA samples under ambient exposure conditions showed no change during the period of study (30 days). Addition of PLA levels lower than $30 \%(\mathrm{w} / \mathrm{w})$ in pre-composted yard waste was suggested for efficient composting as levels $>30 \%$ would decrease $\mathrm{pH}$ due to disintegration of PLA to lactic acid and suppress microbial growth [67]. In a study on composts amended with differing levels of PLA, it was found that the $\mathrm{pH}$ fell to from ca. $\mathrm{pH} 6.5$ to $\mathrm{pH} 3.5$ when PLA was added to composts at $50 \%(\mathrm{v} / \mathrm{v})$ but not at lower levels [103].

It has been reported that PLA degradation in soil is much slower than compost medium because compost has a higher moisture content and temperature range encouraging PLA hydrolysis and assimilation of PLA by thermophilic microorganisms [17]. A 20 month PLA soil burial trial caused $20 \%$ and $75 \%$ degradation of PLA100 (crystalline PLA) and PLA75 (amorphous PLA), respectively [43]. Ohkita and Lee [104], also buried pure PLA and its composites in soil with pure PLA showing little degradation after 6 weeks. When PLA film was buried in soil for 120 days in soil at $25^{\circ} \mathrm{C}$, no degradation was observed as determined by weight loss of the film [105]. Although actinomycete threads were observed on PLA film by scanning electron microscopy (SEM), there were no signs of degradation on the surface of the PLA films [105]. In another study, injection molded tensile bars of PLA buried in soil for 1 year showed no physical changes, no weight change and no significant change in tensile strength [106]. In a study by Calmon et al. [107], twenty different polymer types including PLA were buried in soils in four different areas in France for two years. While PLA was still present after 2 years, some signs of physical degradation were noted [107]. Two other studies have also demonstrated minimal PLA degradation at ambient temperatures. PLA buried in either soil or compost at $25^{\circ} \mathrm{C}$ showed minimal changes after 1 year while a further study although leading to the isolation of several fungi from the surface of PLA again showed no signs of degradation $[89,90]$. Another study over 20 months in soil also showed minimal degradation of PLA films by weight loss, melting point of tensile strength [108]. Therefore while compostable, PLA cannot be regarded as hydrolysable or biodegradable under normal environmental conditions. However by contrast, an open soil burial trial in China indicated significant degradation of PLA after 4 months. Soil temperatures varied between ca $10^{\circ} \mathrm{C}$ at the beginning of the trial and $>20^{\circ} \mathrm{C}$ at the end with an average of $20{ }^{\circ} \mathrm{C}$ [109]. Likewise, a more recent study found little degradation of PLA in soil under mesophilic conditions, but greatly enhanced degradation in thermophilic conditions, particularly when microbes present [110]. Thus, temperature and geographical location may have a significant impact on PLA degradation and further studies are required to understand these variables in more detail.

\subsection{Degradation of PLA in aquatic systems}

In contrast to terrestrial systems, few studies have investigated the biodegradation of PLA in aquatic environments. In both static and dynamic seawater, no evidence of microbial degradation was found after 10 weeks leading the authors to suggest that marine microbes have a limited ability to degrade PLA [111,112] while another study reported little change in molecular weight of PLA rods after 3 months immersion in seawater at $20^{\circ} \mathrm{C}$ although a $48 \%$ reduction was found when immersed in seawater at $40{ }^{\circ} \mathrm{C}$ for 3 months which was attributed to hydrolysis rather than microbial degradation [113].

\section{Conclusion}

The need to find commercially viable degradable plastics manufactured from feed stocks rather than petrochemicals led to the large-scale manufacture of PLA and its subsequent large increase in wide range of compostable materials $[14,15]$. Nonetheless, due to their stability in soils at ambient temperatures, there is a risk of wide scale environmental contamination and environmental issues similar to that seen with conventional plastics [6,114]. However, as a compostable plastic that hydrolyses at elevated temperatures in a process accelerated by the presence of microorganisms, efficient 
waste management strategies to direct PLA plastics to commercial composting facilities will greatly reduce risk $[23,56]$. Moreover, it appears high levels of PLA can be tolerated in the composting process without affecting the $\mathrm{pH}$ and subsequent microbial community activity and therefore compost quality. Despite this, more research is needed to study the long-term impact of large quantities of PLA continually entering commercial composting streams on subsequent compost quality as well as impacts on soils from PLA accumulation and pollution.

\section{References}

[1] R.A. Gross, B. Kalra, Biodegradable polymers for the environment, Science 297 (5582) (2002) 803-807.

[2] M. Flieger, M. Kantorová, A. Prell, T. Rezanka, J. Votruba, Biodegradable plastics from renewable sources, Folia Microbiol. 48 (1) (2003) 27-44.

[3] D. Briassoulis, An overview on the mechanical behaviour of biodegradable agriculturalfFilms, J. Polym. Environ. 12 (2) (2004) 65-81.

[4] K. Madhavan Nampoothiri, N.R. Nair, R.P. John, An overview of the recent developments in polylactide (PLA) research, Bioresour. Technol. 101 (22) (2010) 8493-8501.

[5] R. Chandra, R. Rustgi, Biodegradable polymers, Prog. Polym. Sci. 23 (7) (1998) $1273-1336$.

[6] M. Shimao, Biodegradation of plastics, Curr. Opin. Biotechnol. 12 (2001) $242-247$.

[7] D.F. Williams, Biodegradation of surgical polymers, J. Mater. Sci. 17 (5) (1982) 1233-1246.

[8] R.E. Drumright, Gruber, R. Patrick, D.E. Henton, Polylactic acid technology, Adv. Mater. 12 (2000) 1841-1846.

[9] D. Garlotta, A literature review of Poly (lactic acid), J. Polym. Environ. 9 (2) (2002) 63-84.

[10] G.M. Bohlmann, General characteristics, processability, industrial applications and market evolution of biodegradable polymers, in: C. Bastioli (Ed.), Handbook of Biodegradable Polymers, Rapra Technology Ltd, Shropshire, UK, 2005, pp. $183-212$.

[11] L.-T. Lim, R. Auras, M. Rubino, Processing technologies for poly(lactic acid), Prog. Polym. Sci. 33 (8) (2008) 820-852.

[12] H. Tsuji, Degradation of Poly(lactide)-based Biodegradable Materials, Nova Science Publishers, USA, 2008.

[13] S. Domenek, C. Courgneau, V. Ducruet, Characteristics and applications of poly(lactide), in: S. Kalia, L. Averous (Eds.), Biopolymers: Biomedical and Environmental Applications, Wiley, New Jersey and Scrivener Publishers, Massachusetts, 2011, pp. 183-223.

[14] J. Lunt, Large-scale production, properties and commercial applications of polylactic acid polymers, Polym. Degrad. Stab. 3910 (97) (1998) 145-152.

[15] R. Auras, B. Harte, S. Selke, R. Hernandez, Mechanical, physical, and barrier properties of poly(lactide) films, J. Plastic Film Sheeting 19 (2) (2003) $123-135$.

[16] M. Hakkarainen, Aliphatic Polyesters,: abiotic and biotic degradation and degradation products, Adv. Polym. Sci. 157 (2002) 113-138.

[17] M. Itävaara, S. Karjomaa, J.-F. Selin, Biodegradation of polylactide in aerobic and anaerobic thermophilic conditions, Chemosphere 46 (6) (2002) $879-885$.

[18] R. Auras, B. Harte, S. Selke, An overview of polylactides as packaging materials, Macromol. Biosci. 4 (9) (2004) 835-864.

[19] Y. Tokiwa, B.P. Calabia, Biodegradability and biodegradation of poly(lactide), Appl. Microbiol. Biotechnol. 72 (2) (2006) 244-251.

[20] B.G. Kale, R. Auras, S.P. Singh, Comparison of the degradability of Poly (lactide) packages in composting and ambient exposure conditions, Packag. Technol. Sci. 20 (2007) 49-70.

[21] A. Hao, Y. Geng, Q. Xu, Z. Lu, L. Yu, Study of different effects on foaming process of biodegradable PLA/starch composites in supercritical/compressed carbon dioxide, J. Appl. Polym. Sci. 109 (2008) 2679-2686.

[22] V. Siracusa, P. Rocculi, S. Romani, M.D. Rosa, Biodegradable polymers for food packaging: a review, Trends Food Sci. Technol. 19 (12) (2008) 634-643.

[23] J.H. Song, R.J. Murphy, R. Narayan, G.B.H. Davies, Biodegradable and compostable alternatives to conventional plastics. Philosophical transactions of the royal society of london. Series B, Biol. Sci. 364 (1526) (2009) 2127-2139.

[24] Erwin T.H. Vink, K.R. Rábago, D. a Glassner, B. Springs, R.P. O'Connor, J. Kolstad, P.R. Gruber, The sustainability of NatureWorks polylactide polymers and Ingeo polylactide fibers: an update of the future, Macromol. Biosci. 4 (6) (2004) 551-564.

[25] D. Henton, P. Gruber, J. Lunt, J. Randall, Polylactic acid technology, in: A.K. Mohanty, M. Misra, L.T. Drzal (Eds.), Natural Fibers, Biopolymers, and Biocomposites, CRC Press, Boca Raton, FL, USA, 2005, pp. 527-577.

[26] A.J. Ragauskas, C.K. Williams, B.H. Davison, G. Britovsek, J. Cairney, C.A. Eckert, W.J. Frederick Jr., J.P. Hallett, D.J. Leak, C.L. Liotta, J.R. Mielenz, R. Murphy, R. Templer, T. Tschaplinski, The path forward for biofuels and biomaterials, Science 311 (5760) (2006) 484-489.

[27] C.H. Holten, Lactic Acid. Properties and Chemistry of Lactic Acid and Derivatives, Verlag Chemie GmbH, Weinheim/Bergstr., Germany, 1971.
[28] C.E. Lowe, Preparation of High Molecular Weight Polyhydroxyacetic Ester, Google Patents, 1954, February 2.

[29] R.K. Kulkarni, K.C. Pani, C. Neuman, F. Leonard, Polylactic acid for surgical implants, Archives Surg. 93 (5) (1966) 839-843.

[30] S. Li, M. Vert, Biodegradation of aliphatic polyesters, in: G. Scott (Ed.), Degradable Polymers: Principles and Applications, second ed., Kluwer Academic Publishers, Dordrecht, The Netherlands, 1995, pp. 43-87.

[31] R.J. Müller, Biodegradation behaviour of polymers in liquid environments, in: Catia Bastioli (Ed.), Handbook of Biodegradable Polymers, Rapra Technology Ltd, Shropshire, UK, 2005.

[32] B.P. Mooney, The second green revolution? Production of plant-based biodegradable plastics, Biochem. J. 418 (2) (2009) 219-232.

[33] Erwin T.H. Vink, K.R. Rábago, D. Glassner, P.R. Gruber, Applications of life cycle assessment to NatureWorksTM polylactide (PLA) production, Polym. Degrad. Stab. 80 (3) (2003) 403-419.

[34] Z.P. Lorenc, Techniques for the optimization of facial and nonfacial volumization with injectable poly-l-lactic acid, Aesthetic Plast. Surg. 36 (5) (2012) $1222-1229$.

[35] R.P. John, K.M. Nampoothiri, A. Pandey, Fermentative production of lactic acid from biomass: an overview on process developments and future perspectives, Appl. Microbiol. Biotechnol. 74 (3) (2007) 524-534.

[36] K. Enomoto, M. Ajioka, A. Yamaguchi, Polyhydroxycarboxylic Acid and Preparation Process Thereof, Google Patents, 1994, May 10.

[37] P.R. Gruber, E.S. Hall, J.J. Kolstad, M.L. Iwen, R.D. Benson, R.L. Borchardt Continuous Process for Manufacture of Lactide Polymers with Controlled Optical Purity, Google Patents, 1992, August 25.

[38] S.J. Huang, Poly(lactic acid) and Copolyesters, in: C. Bastioli (Ed.), Handbook of Biodegradable Polymers, Rapra Technology Limited, Shropshire, UK, 2005.

[39] K. Fukushima, J.L. Feijoo, M.-C. Yang, Abiotic degradation of poly(dl-lactide), poly(+-caprolactone) and their blends, Polym. Degrad. Stab. 97 (11) (2012) 2347-2355.

[40] J.J. Kolstad, E.T.H. Vink, B. De Wilde, L. Debeer, Assessment of anaerobic degradation of IngeoTM polylactides under accelerated landfill conditions, Polym. Degrad. Stab. 97 (7) (2012) 1131-1141.

[41] H. Tsuji, Y. Ikada, Stereocomplex formation between enantiomeric poly(lactic acid)s. 6. Binary blends from copolymers, Macromolecules 25 (1992) 5719-5723.

[42] H. Tsuji, Y. Ikada, Crystallization from the melt of poly(lactide)s with different optical purities and their blends, Macromol. Chem. Phys. 197 (1996) 3483-3499.

[43] H. Urayama, T. Kanamori, Y. Kimura, Properties and biodegradability of polymer blends of poly (l-lactide) s with different optical purity of the lactate units, Macromol. Mater. Eng. 287 (2) (2002) 116-121.

[44] M.S. Reeve, S.P. McCarthy, M.J. Downey, R.A. Gross, Polylactide stereochemistry: effect on enzymic degradability, Macromolecules 27 (3) (1994) $825-831$.

[45] M. Vert, J. Mauduit, S. Li, Biodegradation of PLA/GA polymers: increasing complexity, Biomaterials 15 (15) (1994) 1209-1213.

[46] H. Tsuji, K. Ikarashi, In vitro hydrolysis of poly(l-lactide) crystalline residues as extended-chain crystallites. Part I: long-term hydrolysis in phosphatebuffered solution at $37^{\circ} \mathrm{C}$, Biomaterials 25 (2004a) 5449-5455.

[47] G. Perego, G.D. Cella, Mechanical properties, in: R. Auras, L.-T. Lim, H. Tsuj (Eds.), Poly (Lactic Acid): Synthesis, Structures, Properties, Processing, and Applications, John Wiley \& Sons, Inc, New Jersey, USA, 2010, pp. 141-154.

[48] C.M. Agrawal, D. Huang, J.P. Schmitz, K.A. Athanasiou, Elevated Temperature degradation of a 50:50 copolymer of PLA-PGA, Tissue Eng. 3 (4) (1997) $345-352$.

[49] H. Nishida, Y. Tokiwa, Effects of higher-order structure of poly (3hydroxybutyrate) on its biodegradation. II. Effects of crystal structure on microbial degradation, J. Polym. Environ. 1 (1) (1993) 65-80.

[50] H. Tsuji, Hydrolytic degradation, in: R. Auras, L-T. Lim, H. Tsuji (Eds.), Poly (Lactic Acid): Synthesis, Structures, Properties, Processing, and Applications, John Wiley \& Sons, Inc, New Jersey, USA, 2010, pp. 345-382.

[51] K.G. Ho, A.L. Pometto, A. Gadea-Rivas, J.A. Briceno, A. Rojas, Degradation of polylactic acid ( pla ) plastic in Costa Rican soil and Iowa state university compost rows 1, J. Environ. Polym. Degrad. 7 (4) (1999a) 173-177.

[52] H. Tsuji, Y. Ikada, Properties and morphology of poly (L-lactide). II. Hydrolysis in alkaline solution, J. Polym. Sci. Part A Polym. Chem. 36 (1) (1998) 59-66.

[53] H. Tsuji, S. Miyauchi, Poly(L-lactide): VI Effects of crystallinity on enzymatic hydrolysis of poly(L-lactide) without free amorphous region, Polym. Degrad. Stab. 71 (2001) 415-424.

[54] A. Höglund, K. Odelius, A.C. Albertsson, Crucial differences in the hydrolytic degradation between industrial polylactide and laboratory-scale poly(L-lactide), ACS Appl. Mater. Interfaces 4 (5) (2012) 2788-2793.

[55] S.K. Saha, H. Tsuji, Effects of molecular weight and small amounts of D-lactide units on hydrolytic degradation of poly (l-lactic acid), Polym. Degrad. Stab. 91 (8) (2006) 1665-1673.

[56] M. Agarwal, K.W. Koelling, J.J. Chalmers, Characterization of the degradation of polylactic acid polymer in a solid substrate environment, Biotechnol. Prog. 14 (3) (1998) 517-526.

[57] K.G. Ho, A.L. Pometto, P.N. Hinz, Effects of temperature and relative humidity on polylactic acid plastic degradation, J. Environ. Degrad. 7 (2) (1999b) 83-92.

[58] A. Södergård, M. Stolt, Properties of lactic acid based polymers and their correlation with composition, Prog. Polym. Sci. 27 (6) (2002) 1123-1163. 
[59] D. Cam, S. Hyon, Y. Ikada, Degradation of high molecular weight poly (Llactide) in alkaline medium, Biomaterials 16 (11) (1995) 833-843.

[60] K.G. Ho, A.L. Pometto, Effects of electron-beam irradiation and ultraviolet light (365 nm) on polylactic acid plastic films 1, J. Environ. Polym. Degrad. 7 (2) (1999) 93-100.

[61] H. Tsuji, Y. Echizen, S.K. Saha, Y. Nishimura, Photodegradation of poly(L-lactic acid): effects of photosensitizer, Macromol. Mater. Eng. 290 (2005) 1192-1203.

[62] H. Tsuji, Y. Echizen, S.K. Saha, Y. Nishimura, Photodegradation of biodegradable polyesters: a comprehensive study on poly(l-lactide) and poly( $\varepsilon$ caprolactone), Polym. Stab. Degrad. 91 (2006) 1128-1137.

[63] H. Tsuji, Y. Echizen, Y. Nishimura, Enzymatic degradation of poly(l-lactic Acid): effects of UV irradiation, J. Polym. Environ. 14 (2006) 239-248.

[64] B.L.F. Vargas, B.A. Welt, P. Pullammanappallil, A.A. Teixeira, M.O. Balaban, C.L. Beatty, Effect of electron beam treatments on degradation kinetics of polylactic acid (PLA) plastic waste under backyard composting conditions and science, Packag. Technol. Sci. 22 (2009) 97-106.

[65] M.-L. Cairns, G.R. Dickson, J.F. Orr, D. Farrar, K. Hawkins, F.J. Buchanan, Electron-beam treatment of poly(lactic acid) to control degradation profiles, Polym. Degrad. Stab. 96 (1) (2011) 76-83.

[66] A. Torres, S.M. Li, S. Roussos, M. Vert, Poly (lactic acid) degradation in soil or under controlled conditions, J. Appl. Polym. Sci. 62 (13) (1996b) 2295-2302.

[67] V.M. Ghorpade, A. Gennadios, M. Hanna, Laboratory composting of extruded poly(lactic acid) sheets, Bioresour. Technol. 76 (1) (2001) 57-61.

[68] P. Sangwan, D.Y. Wu, New insights into polylactide biodegradation from molecular ecological techniques, Macromol. Biosci. 8 (4) (2008) 304-315.

[69] A. Copinet, E. Legin-Copinet, D. Erre, Compostability of co-extruded starch poly(lactic acid) polymeric material degradation in an activated inert solid medium, Materials 2 (3) (2009) 749-764.

[70] A. Longieras, J.-B. Tanchette, D. Erre, C. Braud, A. Copinet, Compostability of poly(lactide): degradation in an inert solid medium, J. Polym. Environ. 15 (3) (2007) 200-206.

[71] Z. Saadi, A. Rasmont, G. Cesar, H. Bewa, L. Benguigui, Fungal degradation of poly(l-lactide) in soil and in compost, J. Polym. Environ. 20 (2) (2012) $273-282$.

[72] A. Jarerat, Y. Tokiwa, Degradation of poly(l-lactide) by a fungus, Macromol. Biosci. 1 (4) (2001) 136-140.

[73] K. Masaki, N.R. Kamini, H. Ikeda, H. Iefuji, Cutinase-like enzyme from the yeast Cryptococcus sp. Strain S-2 hydrolyzes polylactic acid and other biodegradable plastics, Appl. Environ. Microbiol. 71 (11) (2005) 7548-7550.

[74] M. Watanabe, F. Kawai, S. Tsuboi, S. Nakatsu, H. Ohara, Study on enzymatic hydrolysis of polylactic acid by endogenous depolymerization model, Macromol. Theory Simulations 16 (6) (2007) 619-626.

[75] H. Tsuji, K. Ikarashi, In vitro hydrolysis of poly(l-lactide) crystalline residues as extended-chain crystallites: II. Effects of hydrolysis temperature, Biomacromolecules 5 (2004b) 1021-1028.

[76] H. Tsuji, K. Ikarashi, In vitro hydrolysis of poly(l-lactide) crystalline residues as extended-chain crystallites: III. Effects of pH and enzyme, Polym. Degrad. Stab. 85 (2004c) 647-656.

[77] S.M. Li, H. Garreau, M. Vert, Structure-property relationships in the case of the degradation of massive poly (-hydroxy acids) in aqueous media, J. Mater. Sci. Mater. Med. 1 (4) (1990) 198-206.

[78] J.E. Bergsma, W.C. De Bruijn, F.R. Rozema, R.R.M. Bos, G. Boering, Late degradation tissue response to poly (L-lactide) bone plates and screws, Biomaterials 16 (1) (1995) 25-31.

[79] N. a Weir, F.J. Buchanan, J.F. Orr, G.R. Dickson, Degradation of poly-L-lactide. Part 1: in vitro and in vivo physiological temperature degradation. Proceedings of the Institution of Mechanical Engineers. Part H, J. Eng. Med. 218 (5) (2004a) 307-319.

[80] N.A. Weir, F.J. Buchanan, J.F. Orr, D.F. Farrar, G.R. Dickson, Degradation of poly-L-lactide. Part 2: increased temperature accelerated degradation. Proceedings of the Institution of Mechanical Engineers, Part H J. Eng. Med. 218 (5) (2004b) 321-330.

[81] T. Suyama, Y. Tokiwa, P. Ouichanpagdee, T. Kanagawa, Y. Kamagata, Phylogenetic affiliation of soil bacteria that degrade aliphatic polyesters available commercially as biodegradable plastics, Appl. Environ. Microbiol. 64 (12) (1998) 5008-5011.

[82] H. Pranamuda, Y. Tokiwa, H. Tanaka, Polylactide degradation by an Amycolatopsis sp, Appl. Environ. Microbiol. 63 (4) (1997) 1637-1640.

[83] P. Sangwan, C. Way, D.-Y. Wu, New insight into biodegradation of polylactide (PLA)/clay nanocomposites using molecular ecological techniques, Macromol. Biosci. 9 (7) (2009) 677-686.

[84] A. Jarerat, H. Pranamuda, Y. Tokiwa, Poly (l-lactide) degrading activity in various actinomycetes, Macromol. Biosci. 2 (2002) 420-428.

[85] S. Sukkhum, S. Tokuyama, P. Kongsaeree, T. Tamura, Y. Ishida, V. Kitpreechavanich, A novel poly (L-lactide) degrading thermophilic actinomycetes, Actinomadura keratinilytica strain T16-1 and pla sequencing, J. General Appl. Microbiol. 5 (18) (2011) 2575-2582.

[86] D.F. Williams, Enzymic hydrolysis of polylactic acid, Eng. Med. 10 (1) (1981) $5-7$.

[87] A. Torres, S.M. Li, S. Roussos, M. Vert, Degradation of L- and DL-lactic acid oligomers in the presence of Fusarium moniliforme and Pseudomonas putida J. Environ. Degrad. 4 (4) (1996) 213-223.

[88] a Torres, S.M. Li, S. Roussos, M. Vert, Screening of microorganisms for biodegradation of poly(lactic-acid) and lactic acid-containing polymers
Appl. Environ. Microbiol. 62 (7) (1996) 2393-2397.

89] M. Karamanlioglu, G.D. Robson, The influence of biotic and abiotic factors on the rate of degradation of poly(lactic) acid (PLA) coupons buried in compost and soil, Polym. Degrad. Stab. 98 (10) (2013) 2063-2071.

[90] M. Karamanlioglu, A. Houlden, G.D. Robson, Isolation and characterisation of fungal communities associated with degradation and growth on the surface of poly(lactic) acid (PLA) in soil and compost, Int. Biodeterior. Biodegrad. 95 (part B) (2014) 301-310.

[91] L. Husárová, S. Silvie Pekarová, P. Stloukal, P. Kucharzcyk, V. Verney, S. Commereuc, A. Ramone, M. Koutny, Identification of important abiotic and biotic factors in the biodegradation of poly(l-lactic acid), Int. J. Biol. Macromol. 71 (2014) 155-162.

[92] W. Ebeling, N. Hennrich, M. Klockow, H. Metz, H.D. Orth, H. Lang, Proteinase K from Tritirachium album limber, Eur. J. Biochem. 47 (1) (1974) 91-97.

[93] A. Hoshino, Y. Isono, Degradation of aliphatic polyester films by commercially available lipases with special reference to rapid and complete degradation of poly(L-lactide) film by lipase PL derived from Alcaligenes sp, Biodegradation 13 (2) (2002) 141-147.

[94] Hardaning Pranamuda, A. Tsuchii, Y. Tokiwa, Poly (L-lactide) Degrading enzyme produced by Amycolatopsis sp, Macromol. Biosci. 1 (1)(2001) 25-29.

[95] A. Jarerat, Y. Tokiwa, H. Tanaka, Microbial Poly (l-lactide) degrading enzyme induced by amino acids, peptides, and poly (1 -amino acids), J. Polym. Environ. 12 (3) (2004) 139-146.

[96] F. Li, S. Wang, W. Liu, G. Chen, Purification and characterization of poly(Llactic acid)-degrading enzymes from Amycolatopsis orientalis ssp. orientalis, FEMS Microbiol. Lett. 282 (1) (2008) 52-58.

[97] E. Epstein, The Science of Composting, CRC Press, Boca Raton, USA, 1996.

[98] S. Gajalakshmi, S.A. Abbasi, Solid waste management by composting: state of the art, Crit. Rev. Environ. Sci. Technol. 38 (5) (2008) 311-400.

[99] American Society for Testing and Materials (ASTM) Standards, Standard Specifications for Compostable Plastics, ASTM, West Conshohocken, PA, USA, 1999, pp. D6400-D6404.

[100] K.K.R. Bharadwaj, Improvements in microbial compost technology: a special reference to microbiology of composting, in: S. Khanna, K. Mohan (Eds.) Wealth from Waste, Tata Energy Research Institute, New Delhi, India, 1995, pp. $115-135$.

[101] B. Hellmann, L. Zelles, A. Palojarvi, Q. Bai, Emission of climate-relevant trace gases and succession of microbial communities during open-windrow composting, Appl. Environ. Microbiol. 63 (3) (1997) 1011-1018.

[102] L.R. Cooperband, Composting: art and science of organic waste conversion to a valuable soil resource, Lab. Med. 31 (5) (2000) 283-289.

[103] M. Karamanlioglu, R. Preziosi, G.D. Robson, The compostable plastic poly(lactic) acid causes a temporal shift in fungal communities in maturing compost, Compost. Sci. Util. (2017). In press.

[104] T. Ohkita, S. Lee, Thermal degradation and biodegradability of poly (lactic acid)/corn starch biocomposites, J. Appl. Polym. Sci. 100 (4) (2006) 3009-3017.

[105] M. Kamiya, S. Asakawa, M. Kimura, Molecular analysis of fungal communities of biodegradable plastics in two Japanese soils, Soil Sci. Plant Nutr. 53 (5) (2007) 568-574.

[106] R.L. Shogren, W.M. Doane, D. Garlotta, J.W. Lawton, J.L. Willett, Biodegradation of starch/polylactic acid/poly(hydroxyester -ether) composite bars in soil, Polym. Degrad. Stab. 79 (3) (2003) 405-411.

[107] A. Calmon, S. Guillaume, V. Bellon-Maurel, P. Feuilloley, F. Silvestre, Evaluation of material biodegradability in real conditions-development of a burial test and an analysis methodology based on numerical vision, J. Polym. Environ. 7 (3) (1999) 157-166.

[108] H. Tsuji, A. Mizuno, Y. Ikada, Blends of aliphatic polyesters. III. Biodegradation of solution-cast blends from poly(L-lactide) and poly(e-caprolactone), J. Appl. Polym. Sci. 70 (1998) 2259-2268.

[109] Y.-X. Weng, Y.-J. Jin, Q.-Y. Meng, L. Wang, M. Zhang, Y.-Z. Wang, Biodegradation behavior of poly(butylene adipate-coterephthalate) (PBAT), poly(lactic acid) (PLA), and their blend under soil conditions, Polym. Test. 32 (2013) 918-926.

[110] T. Apinya, N. Sombatsompop, B. Prapagdee, Selection of a Pseudonocardia sp. RM423 that accelerates the biodegradation of poly(lactic) acid in submerged cultures and in soil microcosms, Int. Biodeterior. Biodegrad. 99 (2015) $23-30$.

[111] H. Tsuji, K. Suzuyoshi, Environmental degradation of biodegradable polyesters 1. Poly( $\varepsilon$-caprolactone), poly[(R)-3-hydroxybutyrate], and poly(Llactide) films in controlled static seawater, Polym. Degrad. Stab. 75 (2002a) $347-355$.

[112] H. Tsuji, K. Suzuyoshi, Environmental degradation of biodegradable polyesters 2. Poly(e-caprolactone), poly[(R)-3-hydroxybutyrate], and poly(Llactide) films in natural dynamic seawater, Polym. Degrad. Stab. 75 (2002b) 357-365.

[113] A. Le Duigou, P. Davies, C. Baley, Seawater ageing of flax/poly(lactic acid) biocomposites, Polym. Degrad. Stab. 94 (2009) 1151-1162.

[114] D.K.A. Barnes, F. Galgani, R.C. Thompson, M. Barlaz, Accumulation and fragmentation of plastic debris in global environments, Philosophical Trans. R. Soc. B Biol. Sci. 364 (1526) (2009) 1985-1998.

[115] Yutaka Tokiwa, M. Konno, H. Nishida, Isolation of silk degrading microorganisms and its poly (L-lactide) degradability, Chem. Lett. 28 (4) (1999) 355-356.

[116] Y. Ikura, T. Kudo, Isolation of a microorganism capable of degrading poly-(L- 
lactide), J. General Appl. Microbiol. 45 (5) (1999) 247-251.

[117] H. Pranamuda, Y. Tokiwa, Degradation of poly (L-lactide) by strains belonging to genus Amycolatopsis, Biotechnol. Lett. 21 (10) (1999) 901-905.

[118] K. Nakamura, T. Tomita, N. Abe, Y. Kamio, Purification and characterization of an extracellular poly ( L -lactic Acid ) depolymerase from a soil isolate, Amycolatopsis sp. Strain K104-1, Appl. Environ. Microbiol. 67 (1) (2001) $345-353$.

[119] A. Jarerat, Y. Tokiwa, Poly(L-lactide) degradation by Saccharothrix waywayandensis, Biotechnol. Lett. 25 (5) (1999) 401-404.

[120] A. Jarerat, Y. Tokiwa, H. Tanaka, Poly(l-lactide) degradation by Kibdelosporangium aridum, Biotechnol. Lett. 25 (23) (2003) 2035-2038.

[121] K. Tomita, Y. Kuroki, K. Nagai, Isolation of thermophiles degrading poly (Llactic acid), J. Biosci. Bioeng. 87 (6) (1999) 752-755.

[122] K. Sakai, H. Kawano, A. Iwami, M. Nakamura, M. Moriguchi, Isolation of a thermophilic poly-L-lactide degrading bacterium from compost and its enzymatic characterization, J. Biosci. Bioeng. 92 (3) (2001) 298-300.

[123] K. Tomita, H. Tsuji, T. Nakajima, Y. Kikuchi, K. Ikarashi, N. Ikeda, Degradation of poly (D-lactic acid) by a thermophile, Polym. Degrad. Stab. 81 (1) (2003) 167-171.
[124] K. Tomita, T. Nakajima, Y. Kikuchi, N. Miwa, Degradation of poly (L-lactic acid) by a newly isolated thermophile, Polym. Degrad. Stab. 84 (3) (2004) 433-438.

[125] D. Mayumi, Y. Akutsu-Shigeno, H. Uchiyama, N. Nomura, T. NakajimaKambe, Identification and characterization of novel poly(DL-lactic acid) depolymerases from metagenome, Appl. Microbiol. Biotechnol. 79 (5) (2008) $743-750$.

[126] S. Sukkhum, S. Tokuyama, T. Tamura, V. Kitpreechavanich, A novel poly (L -lactide) degrading actinomycetes isolated from Thai forest soil, phylogenic relationship and the enzyme characterization, J. General Appl. Microbiol. 55 (2009) 459-467.

[127] M.N. Kim, S.T. Park, Degradation of poly (1 -lactide) by a mesophilic bacterium, J. Appl. Polym. Sci. 117 (2010) 67-74.

[128] H.J. Jeon, M.N. Kim, Biodegradation of poly(L-lactide) (PLA) exposed to UV irradiation by a mesophilic bacterium, Int. Biodeterior. Biodegrad. 85 (2013) 289-293.

[129] R. Lipsa, N. Tudorachi, R.N. Darie-Nita, L. Oprică, C. Vasile, C. Chiriac Biodegradation of poly(lactic acid) and some of its based systems with Trichoderma viride, Int. J. Biol. Macromol. 88 (2016) 515-526. 